\title{
Explorando a Função Quadrática com o Software Winplot
}

Josy Rocha - josymatematica@gmail.com.br

Fernando Flores Miragem - fer_miragem@terra.com.br

Programa de Pós Graduação em Ensino de Matemática

Universidade Federal do Rio Grande do Sul

\section{Resumo}

A Matemática contribuiu, e continua contribuindo muito, para o desenvolvimento da tecnologia em geral, e dos computadores em particular. No entanto, na era da computação, a Matemática continua sendo ensinada de forma clássica. Os profissionais da computação sempre olharam para a Matemática e a Física como fonte de tecnologia, mas agora, nós, os profissionais da educação, precisamos olhar para os computadores com a perspectiva da educação matemática.

Neste contexto, nós realizamos um trabalho sobre as funções quadráticas e sua ocorrência nos vestibulares usando o software Winplot. O Winplot é uma ferramenta computacional para a construção de gráficos, disponível gratuitamente na web, ou seja, é um software livre. O objetivo final deste trabalho é que os educandos aprendam a identificar e descrever os efeitos, na parábola, da variação dos coeficientes da equação que descreve a função quadrática. Essa experiência de aprendizagem proporciona aos estudantes uma oportunidade para entender a função quadrática e suas representações, bem como o papel desempenhado por cada um de seus coeficientes.

Palavras - chaves: função quadrática, educação matemática, ferramentas computacionais, Winplot.

\section{Exploring the quadratic function with the software Winplot}

\section{Abstract}

Mathematics has contributed, and still contributes greatly, to the development of technology in general, and computers in particular. However, in the computer era, most of the mathematics is being taught in classical way. The computer professionals have always looked at the Mathematics and Physics as a source to improve the technology, but now, we, the education professionals, must look at computers from the perspective of the mathematical education.

In this context, we performed a work on quadratic functions and their occurrence in the university entrance exams using the computer graphing utility Winplot. The Winplot is a graphical computer tool, available to everyone on the web. The ultimate goal of this work is that the students understand how to identify and describe the effects on a parabola of varying the coefficients in the form of a quadratic function. This learning experience provides an opportunity for students to understand the quadratic functions, their representations and the role of each coefficient in the parabola.

Keyword: quadratic functions, mathematics education, computer graphing utility, Winplot.

\section{Introdução:}

A capacidade de estabelecer relações entre as diferentes áreas do conhecimento é uma habilidade desejável para o bom desempenho, no mundo globalizado de hoje. Nesse contexto, o estudo das funções desempenha um papel importante na formação dos estudantes, visto que, está presente em quase todas as atividades desenvolvidas no mundo contemporâneo. A capacidade de sintetizar uma grande quantidade de 
informações através de uma equação matemática ou da representação gráfica pode ser um grande diferencial. No entanto, a abordagem desse tema no Ensino Básico e Superior, geralmente, deixa muito a desejar: não são poucos os casos em que o educador fornece uma equação e os educandos lançam valores para a variável x e obtêm y, construindo uma tabela para com tais valores formarem pares ordenados que servirão para traçar o gráfico. Nesse sentido as Orientações Curriculares para o Ensino Médio (BRASIL, 2006, pg 72) sugerem que "Sempre que possível, os gráficos das funções devem ser traçados a partir de um entendimento global da relação de crescimento/decrescimento entre as variáveis. A elaboração de um gráfico por meio da simples transcrição de dados tomados em uma tabela numérica não permite avançar na compreensão do comportamento das funções". Saunders e DeBlassio (1995) argumentam que com esse procedimento o educando pode substituir a ideia de que toda função tem um gráfico pela ideia de que toda função têm uma tabela. Além disso, essa abordagem é por demais simplista e não leva a uma análise da relação entre as variáveis ou grandezas envolvidas, perdendo assim a oportunidade de mostrar a importância do aprendizado em Matemática para as demais áreas do conhecimento, ao não mostrar a sua aplicabilidade.

Uma das finalidades do Ensino Médio destacada pela LDB (Brasil, 1996) é a preparação básica para o trabalho e a cidadania do educando, para que ele possa continuar aprendendo, de modo a ser capaz de se adaptar com flexibilidade a novas condições de ocupação ou aperfeiçoamento posteriores. Pozo (1998) alerta que é preciso preparar os alunos para que saibam enfrentar situações e contextos variáveis, que exijam deles novos conhecimentos e habilidades. No que se refere ao ensino de Matemática, Camargo, Rocha e Bayer (2005), sugerem que parte da dificuldade em aplicar os conhecimentos adquiridos e estabelecer relações entre as diversas áreas do conhecimento deve-se a falta de comunicação e planejamento em comum, além de uma linguagem adequada por parte dos educadores. Gravina e Santarosa (1998, p. 73) argumentam que

No contexto da Matemática, a aprendizagem nesta perspectiva depende de ações que caracterizam o 'fazer matemática': experimentar, interpretar, visualizar, induzir, conjeturar, abstrair, generalizar e enfim demonstrar. É o aluno agindo, diferentemente de seu papel passivo frente a uma apresentação formal do conhecimento, baseada essencialmente na transmissão ordenada de 'fatos', geralmente na forma de definições e propriedades.

As orientações tanto dos PCN's (Parâmetros Curriculares Nacionais) quanto das OCEM, no que se refere ao ensino de funções, sugerem uma abordagem a partir do cotidiano dos educandos, buscando sempre correlações com as outras áreas do conhecimento (BRASIL, 1998; BRASIL, 2006).

Segundo as OCEM p.72,

O estudo de funções pode ser iniciado com uma exploração qualitativa das relações entre duas grandezas em diferentes situações: idade e altura; área do círculo e raio; tempo e distância percorrida; tempo e crescimento populacional; tempo e amplitude de movimento de um pêndulo, entre outras. Também é interessante provocar os alunos para que apresentem outras tantas relações funcionais e que, de início, esbocem qualitativamente os gráficos que representam essas relações, registrando os tipos de crescimento e decrescimento (mais ou menos rápido). É conveniente solicitar aos alunos que expressem em palavras uma função dada de forma algébrica, 
por exemplo, $\mathrm{f}(\mathrm{x})=2 \mathrm{x}+3$, como a função que associa a um dado valor real o seu dobro, acrescido de três unidades; isso pode facilitar a identificação, por parte do aluno, da idéia de função em outras situações, como, por exemplo, no estudo da cinemática, em Física. É importante destacar o significado da representação gráfica das funções, quando alteramos seus parâmetros, ou seja, identificar os movimentos realizados pelo gráfico de uma função quando alteramos seus coeficientes.

Outro tema presente no discurso de alguns educadores e estabelecimentos de ensino é a preparação para o vestibular. Muitas escolas de Ensino Básico divulgam como um diferencial do seu projeto pedagógico a intenção de preparar para a vida deixando claro que o objetivo final não é o vestibular. Até aí, não vemos problema algum. Preparar para a vida deve ser o objetivo de todos os projetos pedagógicos. Em nossa opinião o problema surge quando a escola faz questão de esquecer desse momento da vida da maioria dos estudantes do Ensino Básico. Além do que, será que o vestibular está realmente desvinculado do cotidiano do educando? Será que os educadores que fazem parte da elaboração das provas dos vestibulares estão completamente desvinculados das propostas de ensino discutidas pelos seus colegas do Ensino Básico? É possível que em algumas universidades isso aconteça, mas, via de regra, não é o que verificamos nas instituições compromissadas com um ensino de qualidade. Camargo e Rocha (2006) analisaram as provas de Física e Matemática de alguns vestibulares de universidades do Rio Grande do Sul, no que se refere as questões envolvendo razão e proporção. Eles encontraram uma significativa incidência de questões extremamente interessantes, que exigem do candidato raciocínio lógico e uma análise interdisciplinar em desprezo de fórmulas e equações decoradas. É provável que o problema esteja na forma que alguns educadores pensam a preparação para o vestibular. Com isso não estamos nos posicionando em relação ao vestibular, a princípio o acesso ao ensino superior deveria ser garantido a todos os cidadãos, mas em existindo tais provas e sendo tão relevantes para o futuro dos educandos, acreditamos que precisamos encontrar uma maneira de usá-las a nosso favor.

\section{O estudo da função quadrática e o software Winplot}

A utilização do computador no nosso cotidiano está tão enraizada que um problema eventual no fornecimento de energia elétrica pode nos gerar grandes desconfortos. O mundo globalizado é informatizado e, portanto, a utilização do computador como ferramenta no processo de aprendizagem é algo que não pode mais ser ignorado pelos educadores. Valente (1997) já alertava para o fato de que a vida das crianças está tão relacionada com tais ferramentas, que não podemos excluí-las no processo de aprendizagem.

No entanto, a utilização do computador na sala de aula requer uma preparação por parte dos educadores. Piva, Dorneles e Spilimbergo (2009 p. 1053) chamam atenção para o fato de que:

Uma aula em um laboratório de informática pode ser tão tradicional quanto aquela realizada em sala de quadro e giz, se o professor não estiver suficientemente convencido de que o computador pode ser um aliado no processo de ensino aprendizagem,...

Por outro lado, o estudo da função quadrática muitas vezes é feito de forma muito superficial, sem usar todas as suas potencialidades no desenvolvimento de um comportamento crítico e criativo no seu público alvo, o educando. Para as OCEM 
(2006) o estudo da função quadrática deve ser realizado de forma que o aluno consiga estabelecer as relações entre os coeficientes da equação polinomial do segundo grau e a forma do gráfico, sugerindo a exploração da forma fatorada $f(x)=a \cdot(x-m)^{2}+n$ para facilitar a compreensão. Acatamos essa sugestão e trabalhamos a função quadrática e sua abordagem no vestibular, usando o software livre Winplot.

O software Winplot foi desenvolvido pelo professor da Philips Exeter Academy, Richard Parris. O download pode ser feito gratuitamente no site oficial do software: http://math.exeter.edu/rparris.

O primeiro passo, foi aplicar um pré-teste para posterior comparação com um pós-teste e a verificação dos resultados da nossa abordagem do tema função quadrática com a utilização do Winplot.

Após a familiarização com a ferramenta de trabalho os estudantes construíram o gráfico da função $\mathrm{f}(\mathrm{x})=\mathrm{x}^{2} \mathrm{e}$, em seguida, foram questionados sobre os efeitos da variação nos parâmetros da equação quadrática no respectivo gráfico.

Inicialmente, os educandos foram instruídos sobre a utilização do software. Após a familiarização com a ferramenta de trabalho abordamos a função quadrática. $\mathrm{Na}$ equação fatorada $\mathrm{f}(\mathrm{x})=\mathrm{a} \cdot(\mathrm{x}-\mathrm{m})^{2}+\mathrm{n}$, consideramos $\mathrm{a}=1, \mathrm{~m}=0$ e $\mathrm{n}=0$ e os educando construíram o gráfico da função $\mathrm{f}(\mathrm{x})=\mathrm{x}^{2}$. $\mathrm{O}$ passo seguinte foi questioná-los a respeito do papel desempenhado pelo coeficiente " $n$ " na função quadrática. Não demorou muito para alguém dizer: vamos ver no programa! O resultado foi visualizado em gráficos como os mostrados na figura 1 .
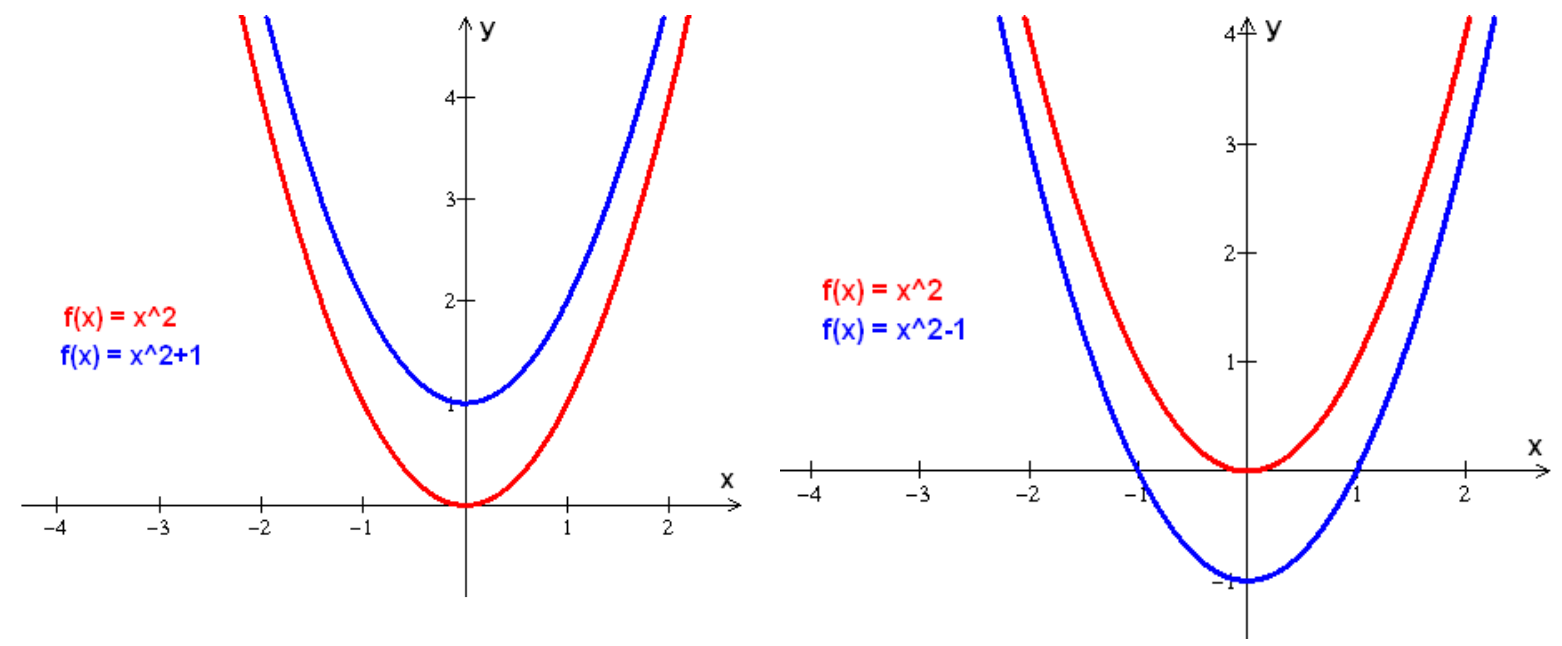

Figura 1 - A variação do coeficiente $n$ leva ao deslocamento vertical da parábola.

Em seguida, consideramos $\mathrm{a}=1$ e $\mathrm{n}=0$ para isolar o efeito do coeficiente $\mathrm{m}$ no gráfico da função quadrática. Os resultados obtidos são similares ao mostrado na figura 2. 

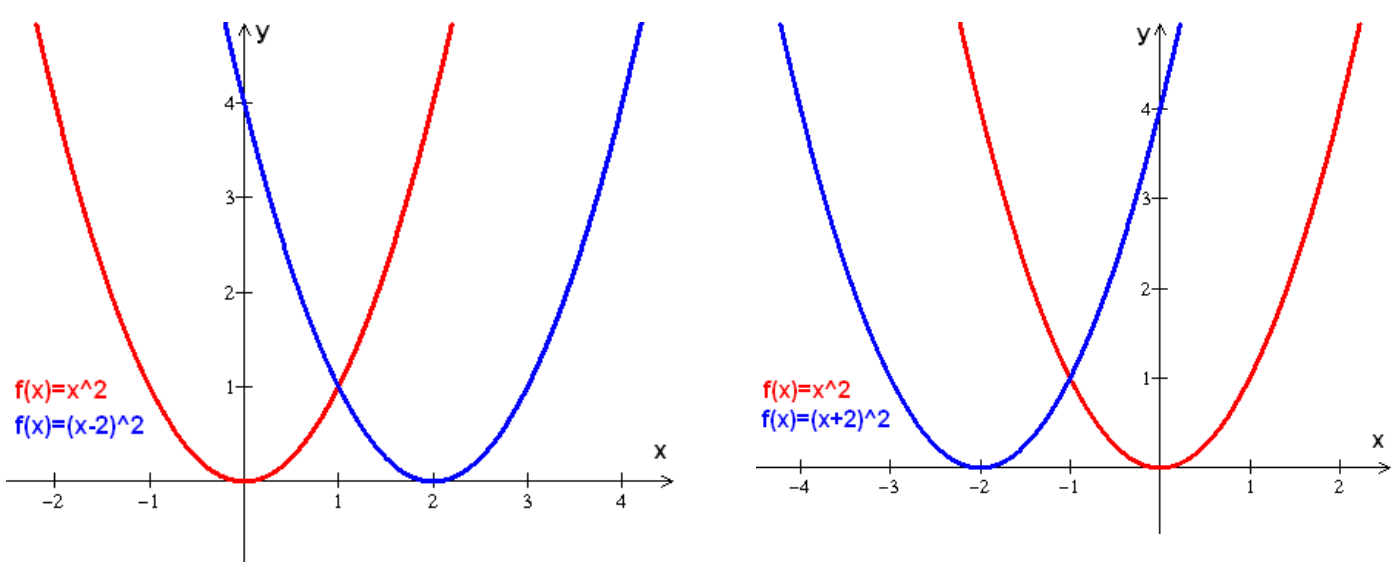

Figura 2 - A variação do coeficiente $m$ leva ao deslocamento horizontal da parábola.

O nosso próximo passo foi questionar sobre os efeitos na representação gráfica da variação dos dois coeficientes $m$ e $n$. A figura 3 mostra o que eles descobriram.
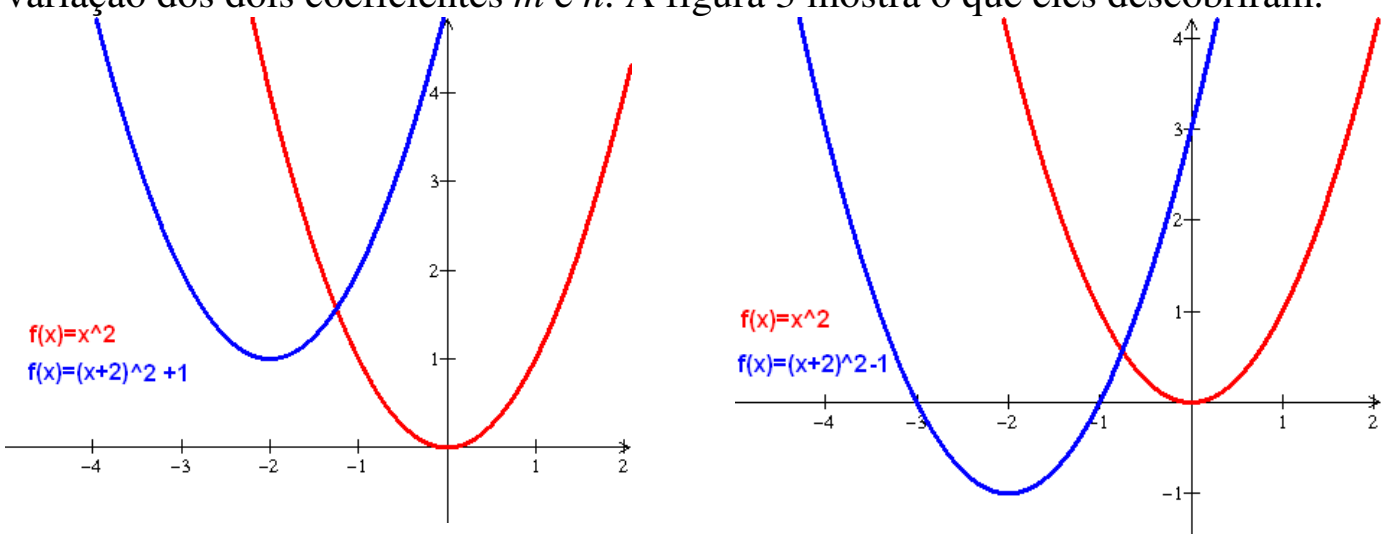

Figura 3 - A variação do coeficiente $n$ leva ao deslocamento vertical da parábola.

Finalmente, questionamos sobre a variação no coeficiente $a$. Os educandos rapidamente perceberam que a mudança no sinal de " $a$ " provoca a reflexão da parábola em relação ao eixo $\mathrm{x}$, ou seja, entenderam o porquê de o " $a$ " positivo indicar concavidade para cima e " $a$ " negativo indicar concavidade para baixo. Ao coeficiente $a$, também foi creditada a responsabilidade pelo movimento de aproximação e afastamento dos pontos da parábola em relação ao eixo de simetria. Os efeitos, acima referidos, podem ser visualizados nos gráficos da figura 4.
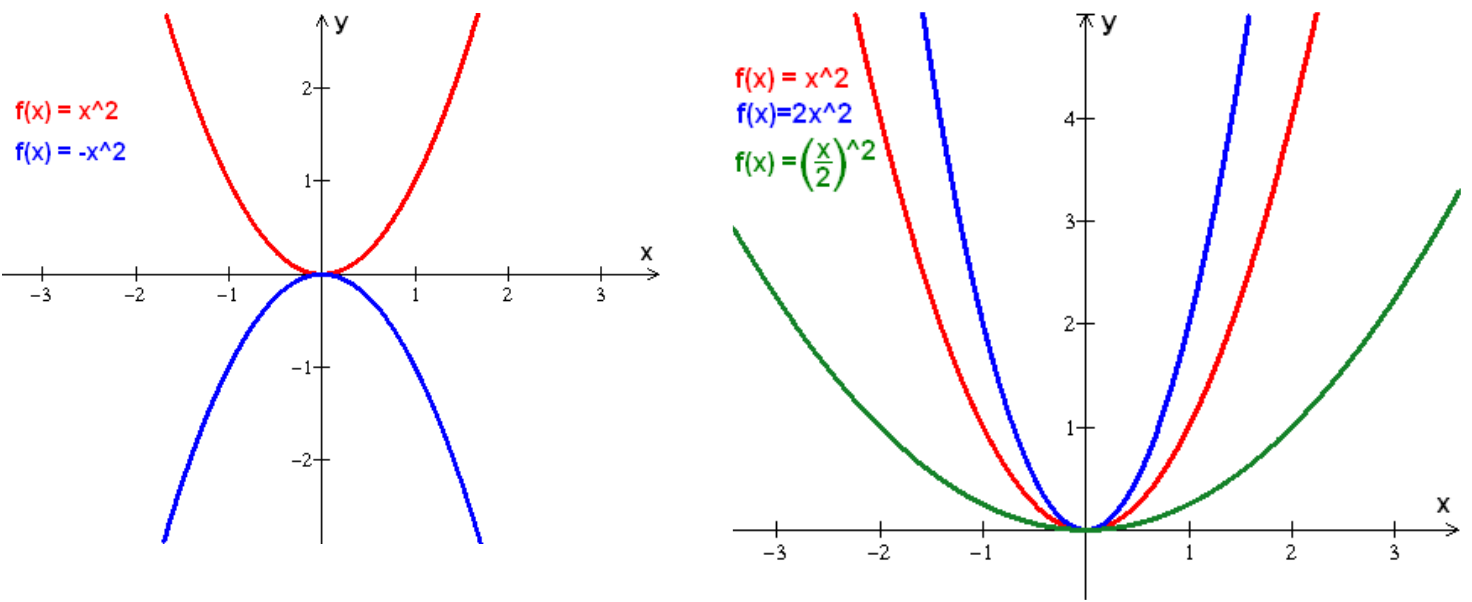

Figura 4 - A variação no sinal do coeficiente $a$ leva a uma reflexão da parábola em relação ao eixo x. A variação no módulo do coeficiente $a$ produz o afastamento ou 
aproximação dos pontos da parábola em relação ao eixo de simetria.

\section{Análise dos resultados}

A nossa amostra é composta de 39 estudantes da terceira série do Ensino Médio. Os estudantes foram submetidos a um teste com sete questões de vestibulares antes e após a atividade com o Winplot.

A tabela 1 e a figura 5 mostram o desempenho dos estudantes em cada questão trabalhada. As questões 1, 3 e 7 estavam diretamente vinculadas ao desenvolvimento da aula e dos exemplos trabalhados com o Winplot e podemos perceber que o desempenho dos estudantes melhorou significativamente no pós-teste. As demais questões abordavam o tema de modo diverso do desenvolvido em aula e, por isso, os avanços foram menos significativos. Nessas questões podemos perceber um aumento no percentual de questões deixadas em branco, o que mostra que estava claro para tais alunos que eles não estavam preparados para tais questões. Esse resultado também é importante, pois mostra algum avanço. É comum nos vestibulares, alunos que não identificam de que assunto determinada questão trata. A questão 6 corrobora essa idéia, pois houve uma redução no percentual de acertos no pós-teste. Obviamente os alunos não desaprenderam o conteúdo. A redução no percentual de acertos é exatamente igual a redução no percentual de estudantes que deixaram a questão em branco, o que sugere que quem se aventurou a responder sem ter melhorado a sua compreensão do assunto errou a questão.

Tabela 1 - Percentuais de respostas certas, erradas e em branco por questão Percentuais (\%)

\begin{tabular}{|rrrr|rrr|}
\multicolumn{1}{c}{ Antes (pré-teste) } & \multicolumn{3}{c}{ Depois (pós-teste) } \\
\hline Questão & Certo & Errado & Branco & Certo & Errado & Branco \\
\hline Questão 1 & $17,9 \%$ & $79,5 \%$ & $2,6 \%$ & $84,6 \%$ & $10,3 \%$ & $5,1 \%$ \\
Questão 2 & $0,0 \%$ & $69,2 \%$ & $30,8 \%$ & $5,1 \%$ & $51,3 \%$ & $43,6 \%$ \\
Questão 3 & $7,7 \%$ & $64,1 \%$ & $28,2 \%$ & $30,8 \%$ & $48,7 \%$ & $20,5 \%$ \\
Questão 4 & $2,6 \%$ & $76,9 \%$ & $20,5 \%$ & $7,7 \%$ & $66,7 \%$ & $25,6 \%$ \\
Questão 5 & $0,0 \%$ & $61,5 \%$ & $38,5 \%$ & $10,3 \%$ & $51,3 \%$ & $38,5 \%$ \\
Questão 6 & $15,4 \%$ & $46,2 \%$ & $38,5 \%$ & $12,8 \%$ & $51,3 \%$ & $35,9 \%$ \\
Questão 7 & $12,8 \%$ & $56,4 \%$ & $30,8 \%$ & $61,5 \%$ & $17,9 \%$ & $20,5 \%$ \\
\hline
\end{tabular}
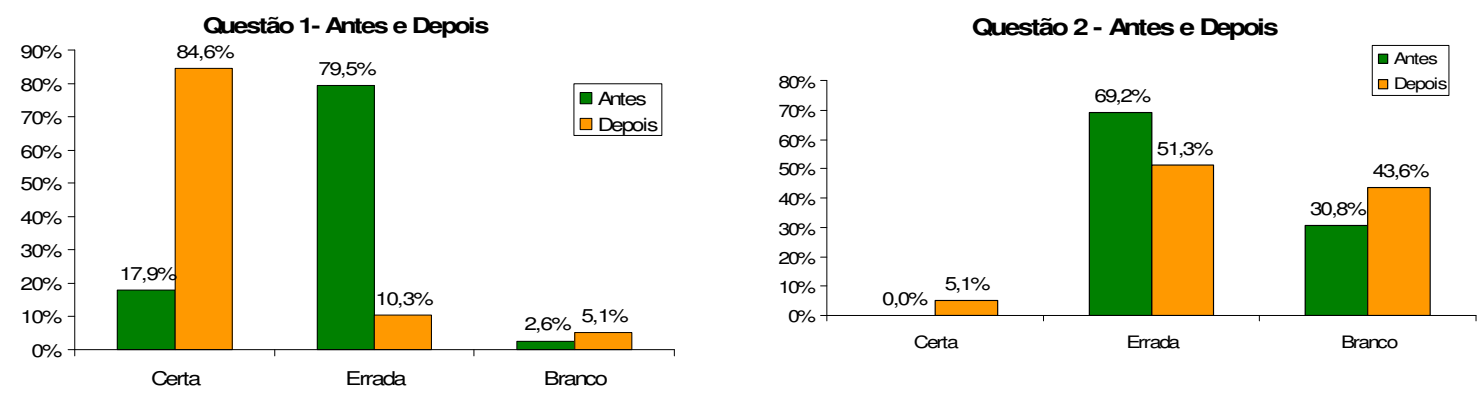

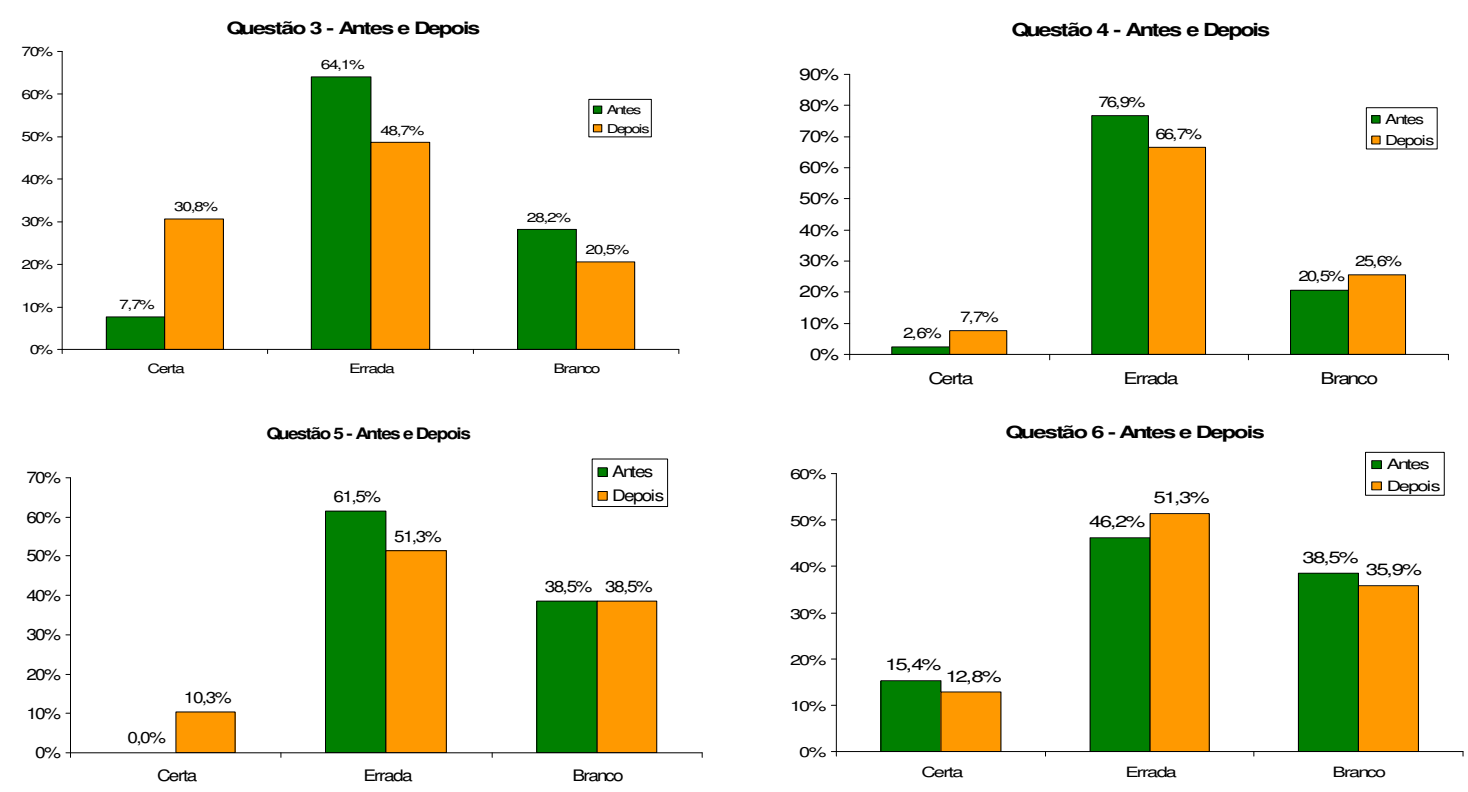

Questão 7 - Antes e Depois

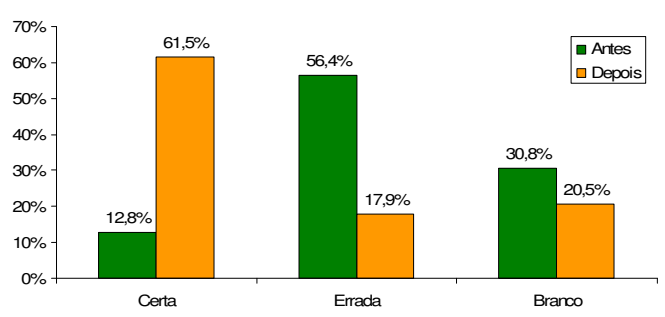

Figura 5 - Desempenho dos estudantes em cada questão, no pré-teste e no pós-teste.

Na figura 6, mostramos o gráfico comparativo dos resultados do pré-teste e pós-teste. O gráfico mostra que a utilização do software livre Winplot melhorou significativamente o desempenho dos estudantes no pós-teste. No entanto, $27,1 \%$ das questões aplicadas não foram respondidas em ambos os testes, provavelmente por ser do conhecimento dos estudantes que o resultado não seria convertido em nota para a disciplina de Matemática. Na dúvida preferiram não se arriscar.

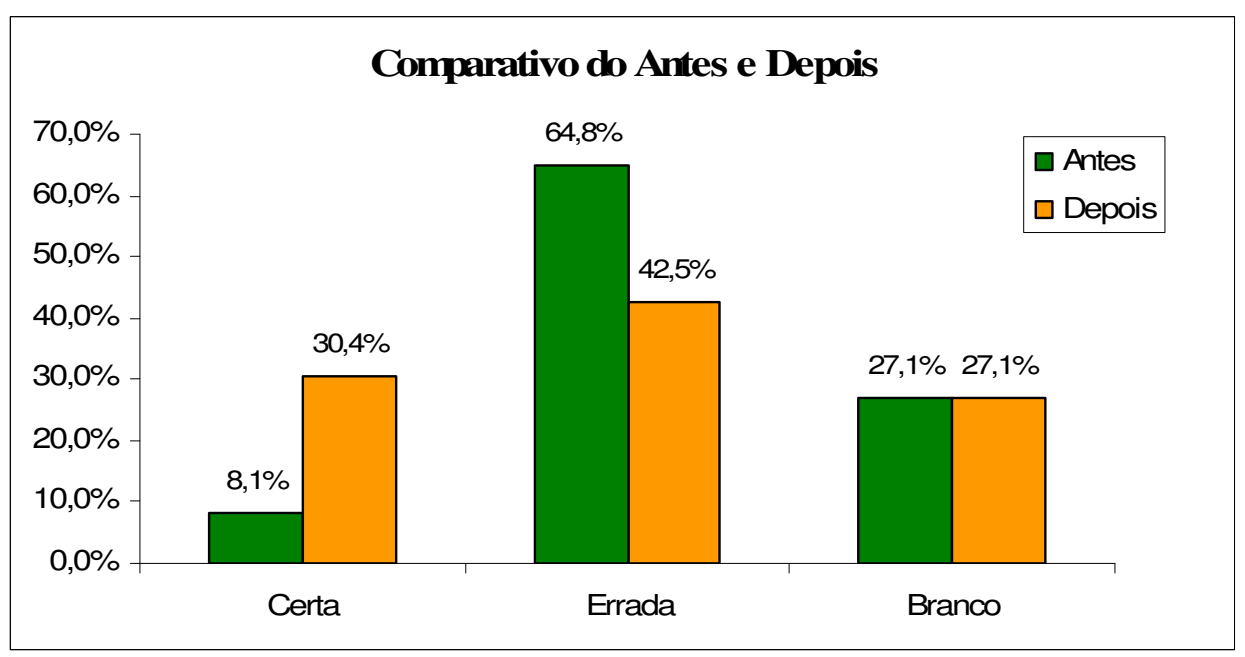

Figura 6 - Gráfico comparativo dos resultados do pré-teste e pós-teste. 
$\mathrm{Na}$ análise dos resultados temos que levar em consideração que as questões aplicadas apresentavam um grau de dificuldade elevado e exigia do educando a capacidade de interpretação e visualização do papel desempenhado por cada coeficiente da equação quadrática no gráfico da função quadrática.

Para finalizar, realizamos uma pesquisa com o objetivo de coletar informações sobre a utilização de aplicativos computacionais nas aulas de Matemática e verificar a receptividade dos estudantes para com esse tipo de trabalho. As questões aplicadas e os respectivos resultados são comentados a seguir:

\section{Q1. Você já utilizou algum software para aprender algo em matemática?}

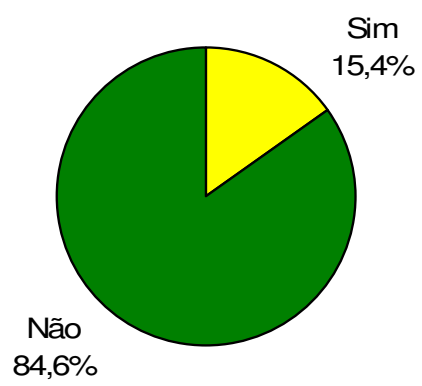

Figura 7 - Resultado da pesquisa sobre a utilização anterior, pelos estudantes, de algum software matemático.

O resultado mostra que os aplicativos computacionais e softwares livres são muito pouco utilizados nas escolas de Ensino Básico.

Q2. No caso da Função quadrática a utilização do software Winplot facilitou a compreensão do conteúdo?

Nesse caso, os estudantes foram unânimes e aprovaram a iniciativa.

Q3 - Em sua opinião, o uso da tecnologia incorporada à sala de aula deveria ser mais difundido?

Novamente, $100 \%$ dos educandos concordam com a necessidade de melhor aproveitamento dos recursos tecnológicos nas escolas de Ensino Básico.

Q4 - Você gostaria de aprender algum conteúdo matemático em especial, com o uso de software?

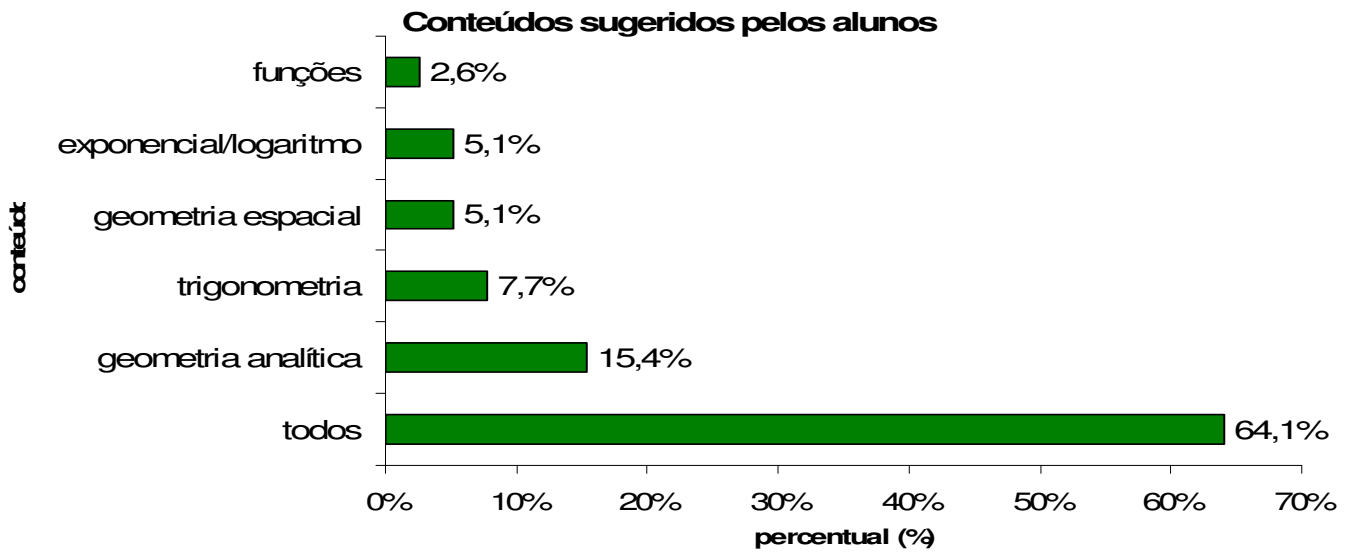

Figura 8 - Expectativa dos estudantes para a utilização de softwares matemáticos . 
Nesse caso, os estudantes não dispõem de informação suficiente para analisar a viabilidade de utilização dos recursos em todos os conteúdos, visto que conhecem poucos softwares dedicados ao ensino da Matemática. No entanto, o gráfico deixa claro que sempre que for possível devemos fazer uso desses instrumentos.

\section{Considerações finais}

Atualmente, o conhecimento de informática é uma necessidade básica no nosso cotidiano. O domínio dessa tecnologia é tão importante que pessoas que as desconhecem estão encontrando dificuldades próximas das enfrentadas pelos analfabetos. No Brasil, até mesmo para exercer o direito de cidadão na escolha dos representantes políticos, tal conhecimento é necessário. Neste contexto, a utilização do computador nas escolas do Ensino Básico deve ocupar posição de destaque na formação dos estudantes.

No presente trabalho, desenvolvemos o estudo das funções quadráticas com a utilização do software livre Winplot. Analisamos o efeito, na parábola, da variação dos coeficientes da equação que descreve a função quadrática. Aplicamos um pré-teste e um pós-teste compostos de questões de vestibulares. Constatamos que a utilização do software Winplot facilitou o entendimento do conteúdo, de modo que o rendimento no pós-teste foi significativo, em relação ao pré-teste. Acreditamos que iniciativas como essas são importantes para que o ensino da Matemática cumpra o seu papel na formação cognitiva e sociocultural dos nossos educandos.

\section{Referências Bibliográficas}

BRASIL, Secretaria de Educação Básica. Orientações Curriculares para o Ensino Médio: Ciências da Natureza, Matemática e suas Tecnologias. Brasília: MEC/SEB, 2006.

BRASIL, Secretaria de Educação Fundamental. Parâmetros Curriculares Nacionais: Matemática. Brasília: MEC/SEF, 1998.

BRASIL. Lei de Diretrizes e Bases da Educação Nacional. Lei nº 9394, de 20 de dezembro de 1996. Estabelece as diretrizes e bases da educação nacional. Brasília, DF, 1996.

CAMARGO, D. S.; ROCHA, J., BAYER, A., Funções e Movimentos uma proposta de integração para as aulas de Física e Matemática. Anais o III Congresso Internacional de Ensino de Matemática. Canoas, 2005.

CAMARGO, D. S.; ROCHA, J., Razão e Proporção nas Provas de Vestibulares do Rio Grande do Sul. XVIII EREM - Encontro Regional de Educação Matemática. São Leopoldo: UNISINOS, 2006. Disponível em: http://www.unisinos.br/eventos/images/stories/erem/razao_proporcao.pdf Acesso em 07 nov. 2009.

GRAVINA, M. A.; SANTAROSA, L. M. C. A aprendizagem da Matemática em Ambientes Informatizados. Revista Informática na Educação - teoria \& prática, v.2, n.1. Porto Alegre: UFRGS, 1999, pg. 73 -88. 
PIVA, C.; DORNELES, L. D.; SPILIMBERGO, A. P. Funções Trigonométricas Inversas em Ambiente Informatizado. In: CNMAC, XXXII, 2009, Cuiabá, MT. Disponível em: http://www.sbmac.org.br/eventos/cnmac/xxxii_cnmac/pdf/186.pdf Acesso em: 12 out. 2010.

POZO, J. I., A solução de problemas. Porto Alegre: Artmed, 1998.

SAUNDERS, J.; DEBLASSIO, J. Relacionando funções com seus gráficos. In : As ideias da álgebra. Org. Arthur F. Coxford e Alberto P. Shulte. São Paulo: Atual, 1995.

VALENTE, J. A. O uso inteligente do computador na educação. Revista Pátio, ano 1, n.1, 1997. 